\title{
Changes in microphytobenthos fluorescence over a tidal cycle: implications for sampling designs
}

\author{
E. Maggi • A. C. Jackson • T. Tolhurst • \\ A. J. Underwood $\cdot$ M. G. Chapman
}

Received: 16 February 2012/Revised: 11 May 2012/Accepted: 19 August 2012

(C) Springer Science+Business Media B.V. 2012

\begin{abstract}
Intertidal microphytobenthos (MPB) are important primary producers and provide food for herbivores in soft sediments and on rocky shores. Methods of measuring MPB biomass that do not depend on the time of collection relative to the time of day or tidal conditions are important in any studies that need to compare temporal or spatial variation, effects of abiotic factors or activity of grazers. Pulse amplitude modulated (PAM) fluorometry is often used to estimate biomass of MPB because it is a rapid, nondestructive method, but it is not known how measures of fluorescence are altered by changing conditions during a period of low tide. We investigated this
\end{abstract}

Handling editor: Stuart Jenkins

\section{E. Maggi ( $₫)$}

Dipartimento di Biologia, Università di Pisa, CoNISMa,

Pisa, Italy

e-mail: emaggi@biologia.unipi.it

A. C. Jackson

Environmental Research Institute, North Highland

College, University of the Highlands and Islands, Ormlie

Road, Thurso, Caithness KW14 7EE, UK

T. Tolhurst

School of Environmental Sciences, University of East Anglia, Norwich NR4 7TJ, UK

\author{
A. J. Underwood · M. G. Chapman \\ Centre for Research on Ecological Impacts of Coastal \\ Cities, Marine Ecology Laboratories A11, University of \\ Sydney, Sydney, NSW 2006, Australia
}

experimentally using in situ changes in minimal fluorescence $\left(F_{\mathrm{o}}^{15}\right)$ on a rocky shore and on an estuarine mudflat around Sydney (Australia), during low tides. On rocky shores, the time when samples are taken during low tide had little direct influence on measures of fluorescence as long as the substratum is dry. Wetness from wave-splash, seepage from rock pools, run-off, rainfall, etc., had large consequences for any comparisons. On soft sediments, fluorescence was decreased if the sediment dried out, as happens during low-spring tides on particularly hot and dry days. Surface water affected the response of PAM and therefore measurements used to estimate MPB, emphasising the need for care to ensure that representative sampling is done during low tide.

Keywords Microphytobenthos - Biomass ·

Sampling $\cdot$ Surface water $\cdot$ Low tide $\cdot$ Pulse amplitude modulated fluorometry $\cdot$ Australia

\section{Introduction}

Intertidal microphytobenthos (MPB) are important primary producers in soft sediments (Yallop et al., 1994; MacIntyre \& Cullen, 1996; Underwood et al., 2005) and on rocky shores (Castenholz, 1961; Nicotri, 1977; Magalhães et al., 2003). They contribute to carbon budgets (Sullivan \& Moncrieff, 1988; Underwood \& Kromkamp, 1999), can stabilize sediments (Tolhurst \& Chapman, 2007) and provide food for 
herbivores (Castenholz, 1961; Hawkins et al., 1992). Spatially, amounts of intertidal MPB vary considerably at scales from millimetres (Blanchard, 1990; Hutchinson et al., 2006; Jackson et al., 2009) to kilometres (Jenkins et al., 2001; Thompson et al., 2005), with a lot of the variation at the smallest scales measured (e.g. Saburova et al., 1995; Chapman \& Tolhurst, 2007). Measures of temporal variation on rocky shores have mostly been about changes at large temporal scales (e.g. monthly, seasonal or inter-annual variability; Underwood, 1984a; Jenkins et al., 2001; Thompson et al., 2005; Jackson et al., 2010), with no studies of short-temporal variation in MPB (e.g. diel or tidal variation). Such large-scale comparisons would, however, be compromised if measures of intertidal MBP abundance are affected by temporal variation throughout periods of low tide. When such variation is not considered, large-scale, seasonal or inter-annual comparisons would be confounded (e.g. Jenkins et al., 2001).

Many intertidal micro-algae in soft sediments have diel and/or tidal migratory behaviour and complex periodicities controlled by availability of light and timing of emersion (Round \& Palmer, 1966; Serôdio et al. 1997; Perkins et al., 2003). Although Lamontagne et al. (1989) suggested that migration by MPB on rocky substrata is unlikely, some species of diatoms are endolithic and migrate in the rock (Houpt, 1994). Migratory patterns (usually upward migration during periods of emersion during daylight hours; Round \& Palmer, 1966; MacIntyre et al., 1996) have been also observed primarily in muddy estuaries which are often dominated by diatoms (e.g. Blanchard et al., 2001; Tolhurst et al., 2003). Composition of MPB assemblages does, however, vary globally. For example, in south-east Australia, rocky shores are often dominated by cyanobacteria (Jackson et al., 2010) and estuaries may have patches of filamentous green algae (Chapman \& Tolhurst, 2004, 2007), which are not migratory. Dominance by these algae in mangrove forests may explain Tolhurst \& Chapman's (2005) results that there was little effect of time of low tide or time during a tidal cycle on concentrations of chlorophyll.

Intertidal systems have emersed and submersed conditions twice daily. Changes in environmental conditions associated with the tide (e.g. temperature, light, water-content, abrasion, etc.) can be stressful to MPB (Joint et al., 1982; Helmuth et al., 2002; Perkins et al., 2003; Easley et al., 2005). Although many studies have shown spatial and temporal variations in chlorophyll (e.g. Blanchard, 1990; Thompson et al., 2004) and photosynthetic activity (e.g. measured by PAM fluorescence; Jesus et al., 2005; Serôdio et al., 2005; Tolhurst et al., 2006), the reasons for these variations are not always clear. They are, however, potentially confounded by variations in the timing of sampling relative to the state of the tide. For example, physiological and physical factors that vary during emersion/submersion (Serôdio et al., 1997; Perkins et al., 2001; Cohn et al., 2003; Roncarati et al., 2008; Coelho et al., 2009) affect these measurements and the timing of sampling is not consistent across sites or larger time-scales. If there is substantial variation from one time to another during the period since the tide fell, it is important to standardise the timing of sampling or to sample at several defined times throughout low tide to be able to compare data from one time or place to another. Otherwise, any difference from time to time (e.g. season to season) may simply reflect differences at different stages of the low-tidal cycle. Despite this requirement, most studies of largescale temporal patterns in MPB biomass have simply reported that sampling was done 'during low tide', without any further information on the timing relative to the state of the tide. Thus, we do not currently know how representative any of these measures of MPB are. Knowing whether, where and when measurements of MPB biomass change during a tidal cycle is therefore essential for planning sampling that is to be comparable across studies or across large spatial or temporal scales.

Methods for sampling and quantifying MPB involve technical difficulties and are time-consuming, particularly on hard substrata (Underwood, 1984b; Hill \& Hawkins, 1990; Nagarkar \& Williams, 1999). Therefore, rapid, non-destructive methods, such as field spectrometry (Murphy et al., 2005a), digital infra-red photography (Murphy et al., 2004; Murphy et al., 2006) and pulse amplitude modulated (PAM) fluorometry (Serôdio et al. 1997; Honeywill et al., 2002; Consalvey et al., 2005; Jesus et al., 2005), have been developed. PAM is a rapid and widely used method, also suitable in systems (such as Mediterranean or Baltic microtidal habitats) where the presence of water (e.g. from wave-splash, seepage from rock pools, run-off, etc.) can prevent the use of alternative non-destructive methods for estimates of MPB abundance. Values of $F_{\mathrm{o}}^{15}$ (minimal fluorescence after 
15 min dark adaptation) have been positively correlated with amounts of chlorophyll $a$ and biomass of MPB (Serôdio et al., 1997; Honeywill et al., 2002).

We used PAM fluorometry to investigate in situ changes in minimal fluorescence $\left(F_{\mathrm{o}}^{15}\right)$ on a rocky shore and on an estuarine mudflat during periods of emersion, to test the hypothesis that fluorescence would vary throughout the period between the fall and the subsequent rise of water during a low tide. We predicted more change (if any) in the sediments, where motile micro-algae were more likely to be present and could more easily migrate vertically compared to the rocky shore. A decrease in fluorescence on the rocky shore was observed as the tide fell and an increase when it rose (see 'Results' section). We proposed the explanation that changes in $F_{\mathrm{o}}^{15}$ were caused by surficial water. This was examined experimentally. On the mudflat, fluorescence decreased during emersion, so we tested whether this was due to water in the surface of the sediment via experiments in which water was either added during low tide or was removed by draining the sediments.

\section{Materials and methods}

Studies were done on a rocky shore in the Cape Banks Scientific Marine Research Area, Botany Bay (hereafter $\mathrm{CB} ; 33^{\circ} 59^{\prime} 54^{\prime \prime} \mathrm{S} ; 151^{\circ} 14^{\prime} 39^{\prime \prime} \mathrm{E}$ ) and on two estuarine mudflats at Tambourine Bay (hereafter TB; $33^{\circ} 49^{\prime} 41^{\prime \prime} \mathrm{S} ; 151^{\circ} 09^{\prime \prime \prime} \mathrm{E}$ ) and Fig Tree Bridge (hereafter FTB; $33^{\circ} 49^{\prime} 44^{\prime \prime} \mathrm{S}$; $151^{\circ} 08^{\prime} 44^{\prime \prime} \mathrm{E}$ ) in Sydney Harbour, NSW. In these areas, tides are semidiurnal with a maximal range of $\sim 2 \mathrm{~m}$. At Cape Banks, rocky epilithic assemblages were dominated by cyanobacteria; in addition, spectral signatures were never similar to assemblages of diatoms (Jackson et al., 2010). During a study of chlorophyll distribution on the Fig Tree Bridge and Tambourine Bay mudflats in Sydney harbour (Murphy et al., 2005b), the shape of the spectra and the peak at green wavelengths indicated that MPB assemblages were dominated by green algae (mostly filamentous green algae, which were distributed on the surface of and in between grains of sediment in the upper few millimetres of the sediment surface) (R. Murphy, pers. comm.). The upper millimetres of the sediment surface has a grain size $<63 \mu \mathrm{m}$ (corresponding to mud) of $24 \%$ at Tambourine Bay and 29\% at Fig Tree Bridge.
Rocky shore

At $\mathrm{CB}$, two randomly selected sites (stretches of $\sim 10 \mathrm{~m}$, about $200 \mathrm{~m}$ apart) at each of two heights on the shore were used. The first ('Mid', about $1.6 \mathrm{~m}$ above Chart Datum) was approximately in the middle of the vertical distribution of an intertidal assemblage of species dominated by grazing molluscs (Underwood, 1980), the most common of which were the limpet Cellana tramoserica (Sowerby) and the snails Bembicium nanum (Lamark) and Nerita atramentosa (Reeve). The second height ('Low', about $1.4 \mathrm{~m}$ above Chart Datum) was where there were more macro-algae, mostly the encrusting red Hildenbrandia rubra (Sommerfelt) Meneghini and brown Ralfsia verrucosa (Areschoug) Areschoug algae. At each site and height, four patches $(30 \times 25 \mathrm{~cm})$ were scrubbed with hydrochloric acid in November 2006 to remove all organisms so that measurements of fluorescence from epilithic MPB were not confused by encrusting macro-algae (Underwood, 1984b). The cleared space was rapidly recolonised by MPB (Murphy et al., 2006) and at 6 months, the reflectance spectra indicated that patches were still colonised by cyanobacteria and possibly some diatoms (R. Murphy, pers. comm.) with no macro-algae.

\section{Observational study}

On March 28th 2007, three replicate measures of fluorescence were taken in each of three 'Mid' patches at one site. Patches were sampled every $5 \mathrm{~min}$, starting when the rock was exposed by the ebbing tide and finishing when the patches were wetted by the rising tide. Care was taken to ensure that the same areas of a patch were not sampled twice.

\section{Experimental addition of water}

An experiment to test the effect of surficial water on fluorescence were done on April 13th and then repeated on May 14th, 2007. At each site and height, two patches were randomly allocated to each of Control and + Water treatments. Control treatments were allowed to dry naturally, and +Water treatments were kept wet throughout low tide by adding seawater from a tank via a perforated rubber hose. Water flow was maintained at a rate that ensured the entire patch was covered by a thin film of water. Fluorescence 
Table 1 Summary of the experimental designs

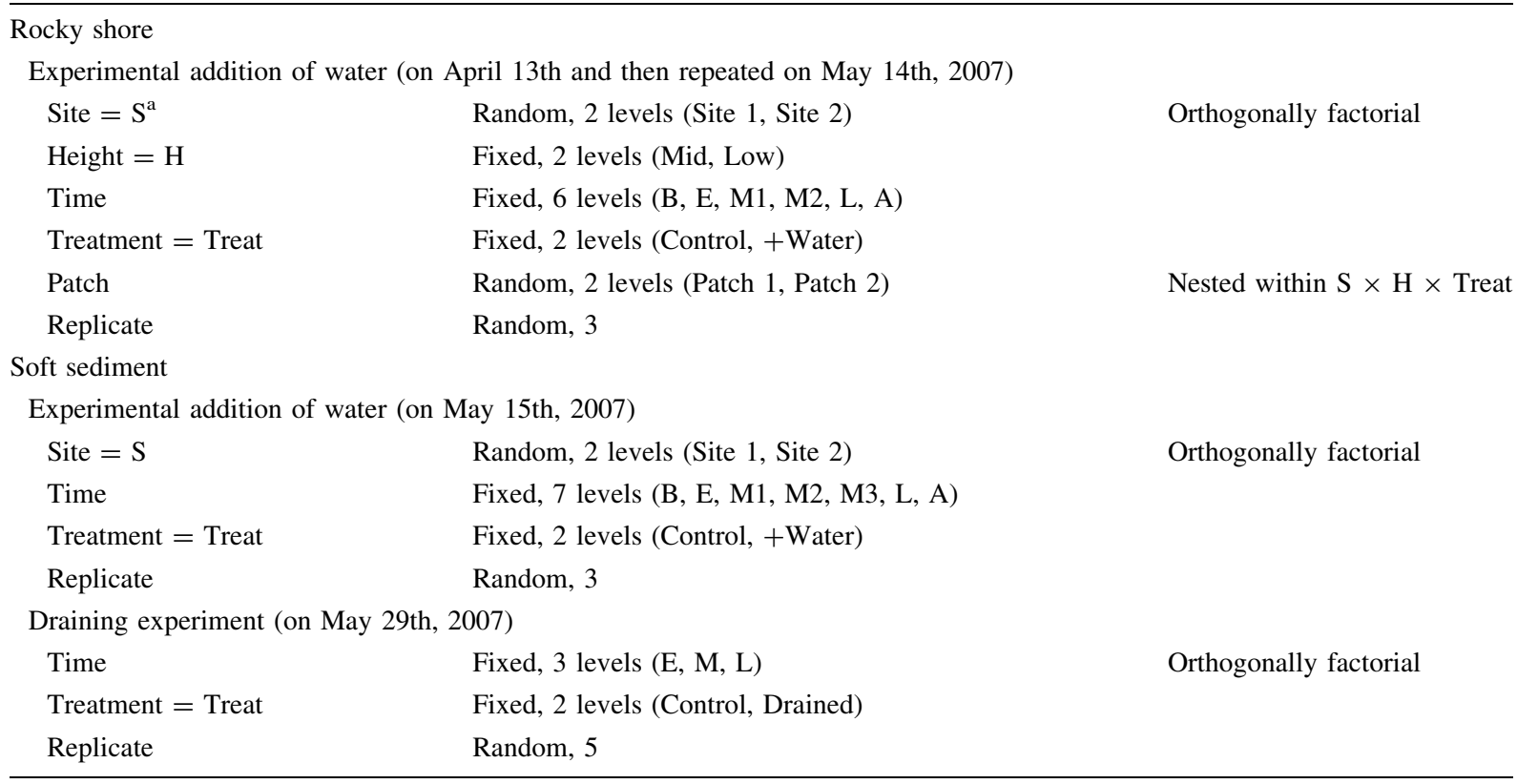

$\overline{\mathrm{B}}=$ just before the mud was emersed; $\mathrm{E}=$ early after emersion; $\mathrm{M} 1, \mathrm{M} 2$ and $\mathrm{M} 3=$ at three times in the middle in the period of emersion; $\mathrm{L}=$ late in the period of emersion; $\mathrm{A}=$ just after the water covered the substratum

${ }^{\text {a }}$ On April 13th, the experiment was done only at Site 1

$(n=3)$ was measured in each patch six times: just before emersion (B; approximately $1 \mathrm{~h}$ before emersion), early during emersion (E; approximately 5-10 min after emersion), twice in the middle of emersion (M1 and M2; approximately 1-1.30 and 2-2.30 $\mathrm{h}$ after emersion, respectively) just before the patches were wetted by the rising tide (L; approximately 3-3.30 h after emersion) and finally just after the rising tide covered the patches (A; approximately 5-10 min after water covered the plot; Table 1). The precise timing of sampling differed among patches, due to sampling constraints and differences in elevation (hence differences in the times of emersion and submersion).

\section{Mudflat}

\section{Observational study}

Changes in fluorescence during emersion were first measured on an intertidal mudflat at TB on March 15th, 2007. Replicate measurements (about $50 \mathrm{~cm}$ apart; $n=168$ ) were taken every $2-5 \mathrm{~min}$ at the same height along a 40-m stretch of shore, starting just after the tide receded and finishing before the water covered the substratum. The same areas were not sampled twice.

\section{Experimental addition of water}

The first experiment to test the effect of presence of water on fluorescence was done on May 15th, 2007, in similar habitat at FTB. In each of two sites ( $40 \mathrm{~m}$ long, $5 \mathrm{~m}$ apart), 42 areas of sediment (150 $\mathrm{mm}$ in diameter) were selected at the same height. These were randomly allocated to Control and + Water treatments. Controls were allowed to dry naturally, and +Water treatments were kept wet throughout the low tide, by retaining water in surrounding plastic rings $(150 \mathrm{~mm}$ in diameter, $200 \mathrm{~mm}$ high) pushed $100 \mathrm{~mm}$ into the mud before the tide ebbed. These were replenished with water as required. Previous experiments had demonstrated that the rings themselves did not affect the fluorescence of algae [mean $F_{\mathrm{o}}^{15}$ in unmanipulated sediment $=429( \pm \operatorname{SE~} 26, n=3) ;$ mean $F_{\mathrm{o}}^{15}$ in sediment inside plastic rings $=416 \quad( \pm$ SE 30 , 
$n=3)]$. Times were: just before the mud was emersed (B; approximately 5-10 min before emersion), early (E; approximately $10-20 \mathrm{~min}$ after emersion), at three times in the middle (M1, M2 and M3; approximately 1, 2 and $3 \mathrm{~h}$ after emersion, respectively), late (L; approximately $4 \mathrm{~h}$ after emersion) during the period of emersion and finally just after the water covered the mud again (A; approximately $10 \mathrm{~min}$ after being covered). The fluorescence for each area was calculated from the mean of three measurements in each plot (Table 1).

\section{Experimental draining}

An experiment to investigate the effect of desiccation of sediment on fluorescence was done on May 29th, 2007, at one of the two sites at FTB. There were two treatments: 15 cores of sediment $(7 \mathrm{~cm}$ in diameter, $5 \mathrm{~cm}$ deep) were drained during a low tide (Drained) and 15 cores were left as Controls. The drained cores were removed from the mudflat at the start of low tide and placed on a rigid mesh sheet raised above the substratum. The sediment was coherent, and the cores did not disintegrate. The surfaces of the cores were not touched during this procedure. This treatment let the sediment drain faster than the Control cores which were left in situ. At each of three times [Early (E; approximately $15 \mathrm{~min}$ after emersion), $\operatorname{Mid}(\mathrm{M}$; approximately $1.3 \mathrm{~h}$ after emersion) and Late (L; approximately $3 \mathrm{~h}$ after emersion)], fluorescence was measured in five randomly chosen cores of each treatment (Table 1).

\section{Measurement of fluorescence}

Algae were dark-adapted for $15 \mathrm{~min}$ (Kromkamp et al., 1998; Honeywill et al., 2002) and minimal fluorescence $\left(F_{\mathrm{o}}^{15}\right)$ measured with a PAM fluorometer (Diving PAM, Walz, Germany; used settings: $\mathrm{MI}=12, \mathrm{G}=9$ ). The probe was kept at $4 \mathrm{~mm}$ above the substratum and measured an area of approximately $24 \mathrm{~mm}^{2}$. The zero offset (measurement of background signal without a sample) was done by pointing the fibre-optic cable at the sky away from the sun. Where two fluorometers were used concurrently on the rocky shore, they were cross-calibrated using measurements of fluorescence standards to ensure comparability of data between devices. Correlations were linear and strong (e.g. $r=0.99$, d.f. $=8, P<0.001$ ).

\section{Results}

Rocky shore

\section{Observational study}

Minimal fluorescence $\left(F_{\mathrm{o}}^{15}\right)$ decreased rapidly when micro-algae were first emersed, remained nearly constant during low tide and then increased rapidly again when the substratum was wetted by the rising tide (Fig. 1).

\section{Experimental addition of water}

In general, decreases in $F_{\mathrm{o}}^{15}$ were smaller where the experimental rock surfaces were kept wet through the low tide than in controls which dried (Fig. 2).

On April 13th, one PAM developed a fault, so data were only collected from one site in the first run of the experiment. There was a significant interaction between Time and Patch (Treatment) (ANOVA; $\left.F_{20,96}=2.31, P<0.01\right)$; but the patterns of change among patches were similar for each treatment, differing only in magnitude. SNK tests on the significant interaction between Time and Treatment $\left(F_{5,5}=4.32, P<0.01\right)$ showed less fluorescence in Control samples between M1 and L than at other times (Fig. 2a), but this was not the case in patches where

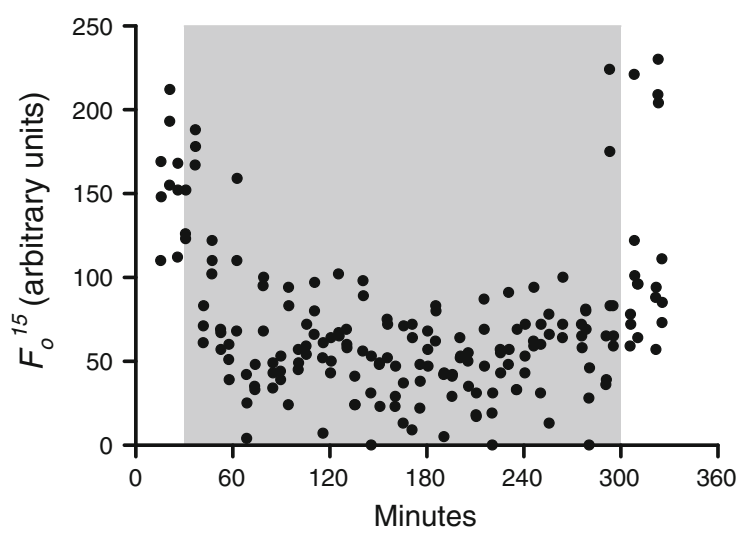

Fig. 1 Individual $F_{\mathrm{o}}^{15}$ from micro-algae on a rocky shore (CB; Site 1, high level) every 5 min during a diurnal low tide, starting when patches were still slightly submerged and finishing just after they were covered again by the rising tide. Low tide was at 11.25 a.m. on 28/03/2007. For this and the subsequent two figures, fluorescence is plotted against the time ( $\mathrm{min}$ ) elapsed since the start of the experiment and grey shading indicates when experimental patches were emersed 
Fig. 2 Mean $( \pm \mathrm{SE} ; n=3)$ $F_{\mathrm{o}}^{15}$ values in control (filled circle) and +Water (open circle) treatments on a rocky shore $(\mathrm{CB})$ at different

Times $(\mathrm{B}=$ before emersion, $\mathrm{E}=$ early, $\mathrm{M} 1=$ middle 1 ,

$\mathrm{M} 2=$ middle $2, \mathrm{~L}=$ late in the emersion period, $\mathrm{A}=$ after the rising tide recovered the patches) for a April 13th 2007, low tide at 11.05, one site and b May two sites. Different letters indicate means that differed significantly among times $(P<0.05)$ for Control patches. Asterisks indicate means that differed significantly between Control and + Water treatments $(* P<0.05$; $* * P<0.01)$ 14th 2007, low tide at 11.50,
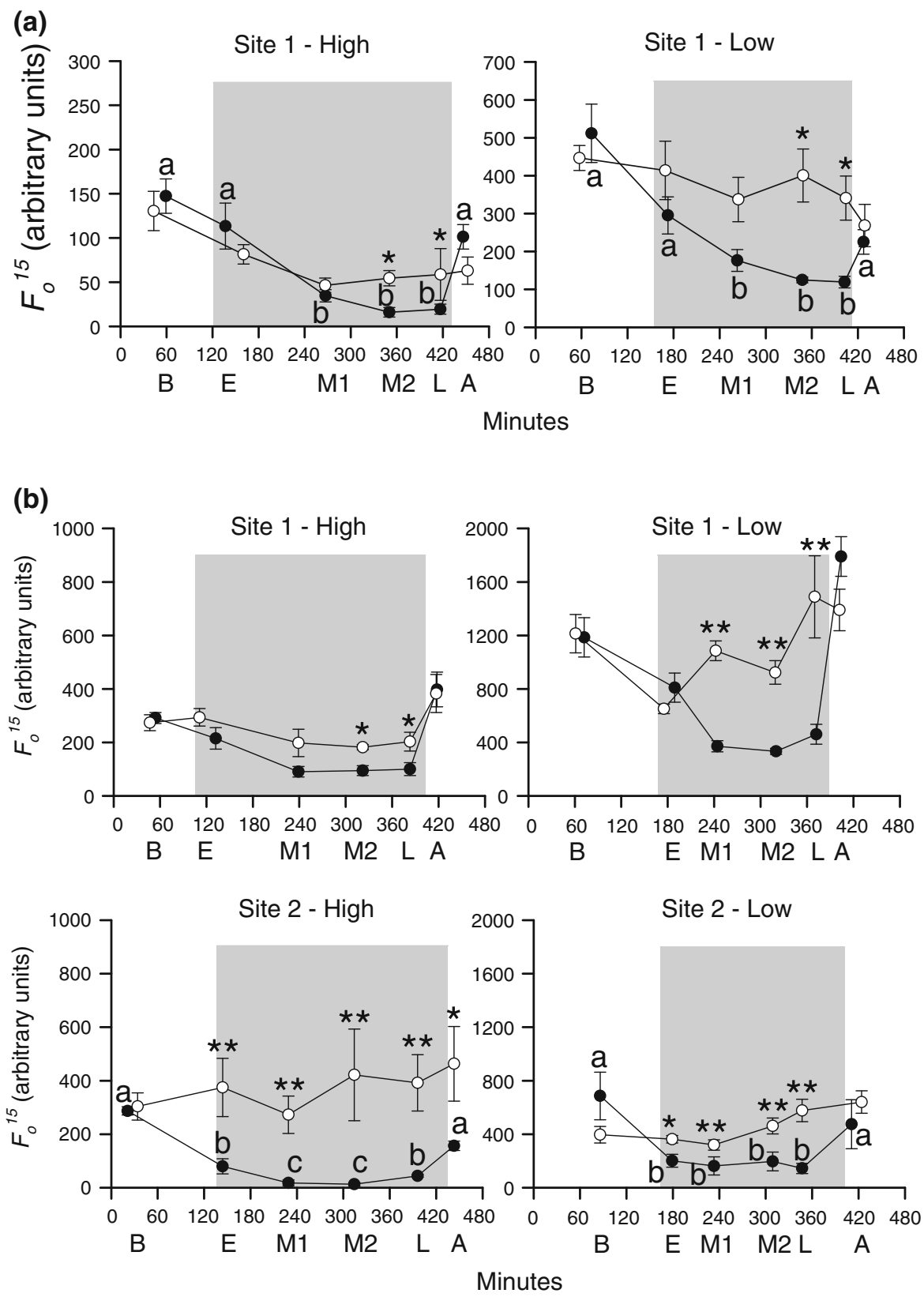

water was added. At Times M2 and L, fluorescence in Control patches was significantly less $(P<0.05)$ than in + Water patches (Fig. 2a). It is worth noting that, at the High height, values of $F_{\mathrm{o}}^{15}$ were very small $(<100)$ during the emersion period (i.e. between Times $\mathrm{E}$ and L), so that results have to be interpreted with caution.

In the second run of the experiment, fluorescence varied between sites and heights on the shore (a significant interaction Height $\times$ Site $\times$ Treatment $\times$ Time, $\left.F_{5,187}=4.59, P<0.01\right)$. In Controls at Site 2, $F_{\mathrm{o}}^{15}$ was greater when the substratum was wet (at the beginning and end of the experiment) than during emersion (Fig. 2b). This was similar at Site 1, although differences were not statistically significant (Fig. 2b). When Control patches were dry (i.e. between Times $\mathrm{E}$ and $\mathrm{L}$ ), measurements of $F_{\mathrm{o}}^{15}$ were 
generally larger in the + Water treatment than in the Controls. In 13 of the 16 comparisons (2 Heights, 2 Sites and 4 Times [E, M1, M2, L]), $F_{\mathrm{o}}^{15}$ was significantly greater in + Water than in Controls (at $P<0.05$ in SNK tests). The probability of 13 of 16 cases in the same direction is small $(P<0.05$, Binomial test).

In some analyses, variances were heterogeneous among samples, but results were considered interpretable because of the large number of degrees of freedom in the analyses (Underwood, 1997). At the last time of sampling (A) on the rocky shore, some dark adaptation chambers were washed away by large waves. To maintain a balanced design, missing data were replaced by the mean value obtained from the remaining replicates in the same treatment; the number of degrees of freedom was correspondingly reduced (Underwood, 1997).
Mudflats

\section{Observational study}

At TB, fluorescence decreased slightly and became less variable as the period of low tide progressed (Fig. 3a), although data were only collected during the period of emersion and it was not possible to see whether fluorescence increased again on re-submersion.

\section{Experimental addition of water}

At FTB, maintaining overlying water during low tide showed no interactions among Site, Treatment and Time, so non-significant interactions $(P>0.25)$ were pooled (Underwood, 1997). $F_{\mathrm{o}}^{15}$ slightly decreased during low tide (ANOVA, $F_{6,69}=3, P<0.05$;
Fig. 3 a Individual $F_{\mathrm{o}}^{15}$ from micro-algae on an estuarine mudflat (TB) every $2-5$ min during a diurnal low tide (at 11.45, on March 15th 2007), starting after emersion and finishing just before sediment was covered by the rising tide. b Mean $( \pm \mathrm{SE} ; n=3) F_{\mathrm{o}}^{15}$ in Control (filled circle) and + Water (open circle) treatments on the mudflat (FTB) at different Times ( $\mathrm{B}=$ before emersion, $\mathrm{E}=$ early, $\mathrm{M} 1=$ middle 1 , M2 = middle 2,

M3 = middle $3, \mathrm{~L}=$ late in the emersion period, $\mathrm{A}=$ after the rising tide recovered the patches) on May 15 th 2007 , low tide at 12.30
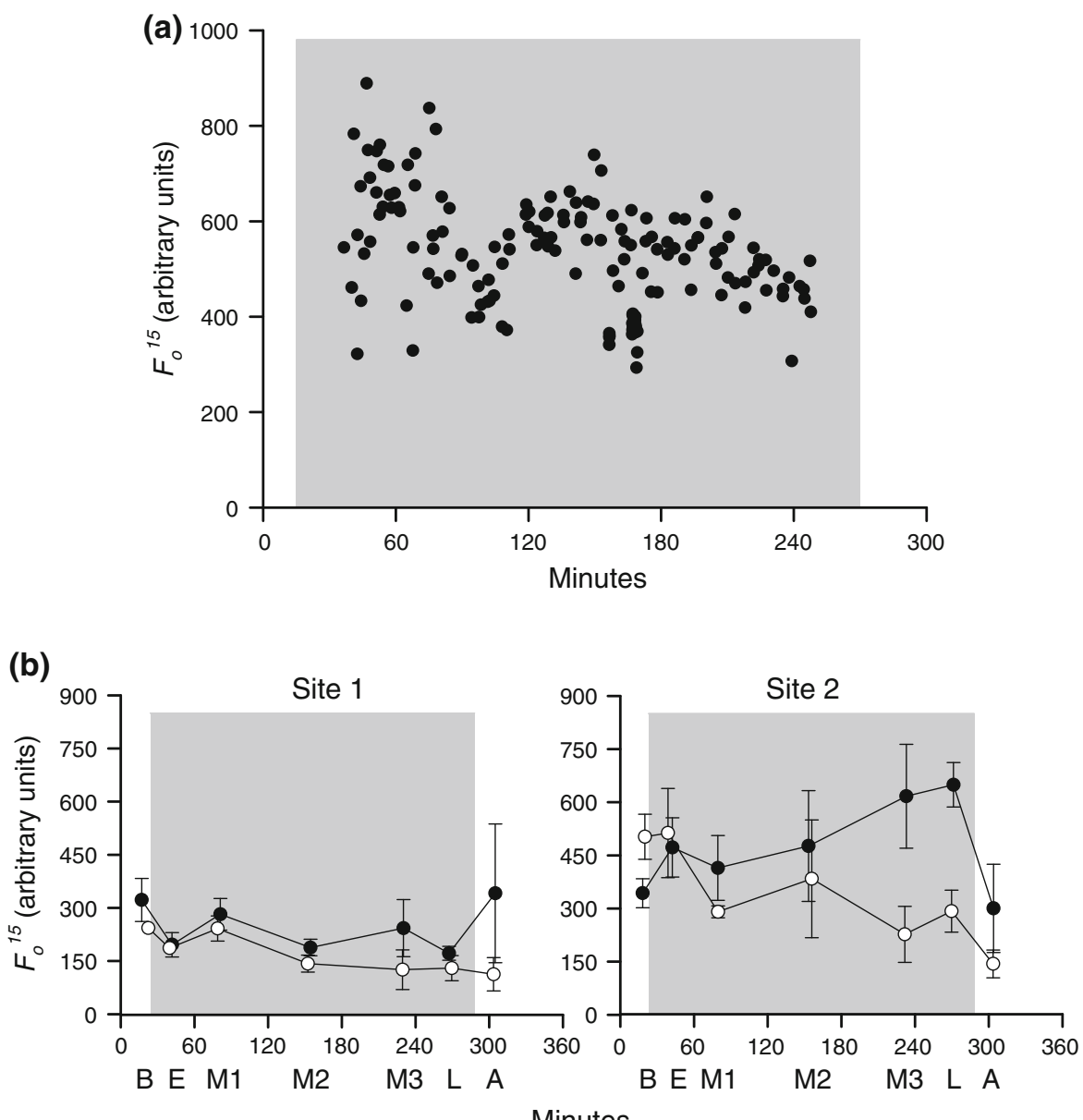


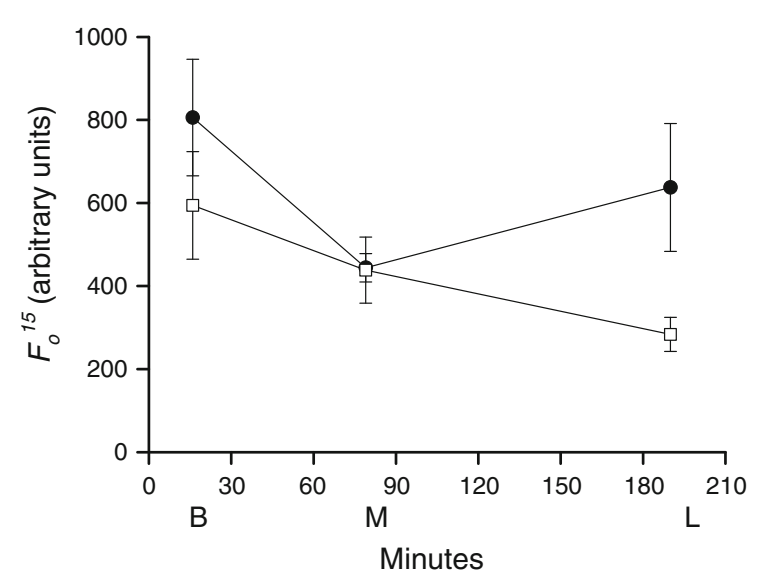

Fig. 4 Mean $( \pm \mathrm{SE} ; n=5) F_{\mathrm{o}}^{15}$ in Control cores (filled circle) and experimentally drained cores (open square) on a mudflat (FTB) during low tide (at 12.00) on May 29th 2007

Fig. 3b), although SNK tests were unable to detect the differences among times. In contrast to the rocky shore, fluorescence did not increase when the Control sediment was covered again by the tide. Values of $F_{\mathrm{o}}^{15}$ were consistently and significantly greater $\left(F_{1,69}=\right.$ 13.0, $P<0.01$; Fig. 3b) in Controls than in + Water treatments, which was opposite to the prediction, although both treatments decreased during low tide. Thus, there was no support for the model that the absence of water overlying the sediment during low tide decreases the measures of $F_{\mathrm{o}}^{15}$ in these MPB.

\section{Experimental draining}

When samples of sediment were drained, $F_{\mathrm{o}}^{15}$ was smaller than in Control samples $\left(F_{1,24}=4.89\right.$, $P<0.05)$ and, again, measures decreased during the period of emersion (Time: $F_{2,24}=3.97, P<0.05$; Beginning $>$ Middle $=$ Late, SNK tests at $P=0.05$ ). Towards the end of low tide, fluorescence of Control samples increased slightly, whilst fluorescence in Drained samples continued to decrease (Fig. 4), although these trends were not significant.

\section{Discussion}

Methods of measuring fluorescence, for example, to estimate MPB biomass that do not depend on the time of collection relative to the time of day or tidal conditions are fundamentally important. In intertidal habitats, numerous environmental variables at the surface of the substratum are likely to change with cover of water, e.g. temperature (especially of the rock, Helmuth \& Hofmann, 2001), light, moisture, gas supply and $\mathrm{pH}$. Each of these may affect photosynthetic reactions, such as non-photochemical quenching (NPQ), as a consequence of photo-inhibition (Falkowski \& Kiefer, 1985; Hanelt, 1992; Henley et al., 1992; Hader et al., 1997). Desiccation of algae has been demonstrated to cause reductions in fluorescence (e.g. Dring \& Brown, 1982; Huppertz et al., 1990; Ji \& Tanaka, 2002, Coelho et al., 2009) and measures of MPB using spectrometry on muddy sediments (Coelho et al., 2009), but not using field spectrometry or digital imaging on rock platforms (Murphy et al., 2006). Resuspension of algae in the water above the sediment (Heckman, 1985) may decrease fluorescence, whilst compaction of sediment during de-watering (Perkins et al., 2003) can increase concentrations of micro-algae.

Here, we examined variation in in situ fluorescence emitted by MPB during a single tidal cycle, because many physiological and physical processes indicated that fluorescence might vary at this scale. For example, although previous studies in soft sediments have shown $F_{\mathrm{o}}^{15}$ to be strongly correlated with biomass of MPB (Serôdio et al., 1997; Honeywill et al., 2002), Jesus et al. (2006) warned against sampling at the end of the period of emersion, after showing that differing tendencies of algae to migrate can lead to biased estimates of biomass. Although vertical migration of MPB on rocky substrata may be less important (Lamontagne et al., 1989), tube-dwelling diatoms can move in a mucilaginous sheath (Houpt, 1994), thus affecting the distance from the sensor and hence intensity of fluorescence. In addition, some boring cyanobacteria (forming both epilithic and endolithic filaments) are present on intertidal rock surfaces (Golubic, 1969).

On a rocky shore, we showed that in situ fluorescence emitted by MPB changed little, on average, during most of the period of low tide (Figs. 2, 3). There was, however, a sharp decrease in $F_{\mathrm{o}}^{15}$ as the water drained, and an increase immediately after the rock was wet again by the rising tide. We demonstrated experimentally that this was due to the loss and addition of surficial water, thus excluding the possibility of an effect solely due to endogenous circadian or tidal rhythms on photosynthetic activity (Suzuky \& 
Johnson, 2001). In fact, although changes in abiotic factors (e.g. desiccation, pH, gas supply), vertical migration and/or NPQ processes could possibly decrease $F_{\mathrm{o}}^{15}$ values during the period of emersion in Control patches, in most of the cases, the presence of water reduced this effect. In addition, it is worth stressing that our rocky MPB assemblages were strongly dominated by cyanobacteria (Jackson et al., 2010), which are known to modulate excessive light harvesting processes mostly through state transitions (Campbell et al., 1998). Although NPQ processes in these organisms can be activated by high levels of blue light (see the review by Bailey \& Grossman, 2008), this was not the case for our study, as the Diving PAM excited fluorescence by pulse modulated red light. Last, but not least, it is important to note that the observed increases in $F_{\mathrm{o}}^{15}$ values in Control patches, from just before to just after the water covered them (Fig. 2a and b, see Late and After times), are unlikely to be due to decreases in PAR (photosynthetically active radiation) values. In fact, in both runs of the experiment, the difference in time between the two measurements was about half an hour (and measurements were taken approximately between 2 and 3 p.m.), which is a very short period of time in comparison to the total length of the dry period, which encompassed about $4 \mathrm{~h}$ (approximately between 10 a.m. and 2.30 p.m.), during which MPB experienced greater changes in PAR values.

On rocky shores, the time of sampling during low tide may have little influence on measures of fluorescence as long as the substratum is dry. Wetness (e.g. from wave-splash, seepage from rock pools, run-off, rainfall, etc.) may have large consequences for any comparisons. For example, comparisons of MPB biomass at different heights on a shore or between sheltered and exposed sites may be confounded if low shore or wave-exposed sites are consistently wetter than high shore or sheltered sites. We are, however, not aware of studies using PAM on rocky shores that have considered surface moisture when sampling, although Murphy et al. (2006) demonstrated clearly that surface films of moisture do not affect measures of MPB biomass using field spectrometry or digital imaging. This suggests that surface water does not affect the behaviour of the algae (i.e. NPQ processes or vertical migration) on rock surfaces, but seems to affect directly the measures made by the PAM, i.e. the relationship between MPB biomass and $F_{\mathrm{o}}^{15}$. Recent measurements on a Mediterranean temperate rocky shore showed that the relationship between biomass of MPB (estimated as $\mu \mathrm{g} \mathrm{chl} a / \mathrm{cm}^{2}$ ) and $F_{\mathrm{o}}^{5}$ varied on wet versus dry sandstone rock surfaces (equations from Maggi et al., unpublished data; wet surface: MPB biomass $=0.004 \cdot F_{\mathrm{o}}^{5}+0.26$; dry surface: $\mathrm{MPB}$ biomass $=0.013 \cdot F_{\mathrm{o}}^{5}+0.32$ ).

On soft sediments, changes in the fluorescence during low tide differed from those on the rocky shore. Here fluorescence slightly decreased during emersion; it is worth noting, however, that this result was mainly in the '+Water' treatment. Although this is in contrast to some studies (Serôdio \& Catarino, 2000; Jesus et al., 2005; Tolhurst et al., 2006), which showed increases in fluorescence during low tide, the lack of changes in Control plots during low tide agrees with past experiments at the same location (Tolhurst \& Chapman, 2005). Other authors (Easley et al., 2005) showed that diatoms in a sandy beach did not always migrate vertically during low tide. Here, we cannot exclude an interactive effect between vertical migration of algae and NPQ processes (Falkowski \& Kiefer, 1985). Upward migration in Controls during the period of low tide was, however, very unlikely at these sites, due to a relative scarcity of migratory micro-algae (Chapman \& Tolhurst, 2004, 2007). As a consequence, we should expect only a possible decrease in $F_{\mathrm{o}}^{15}$ values, due to NPQ processes, only in the Control in comparison to the + Water plots (if the presence of some centimetres of water in + Water treatments protected MPB from NPQ processes) or in both Control and +Water plots (if the presence of water did not protect MPB). None of the two alternatives were in accordance with our results. The addition of water may have slightly decreased $F_{\mathrm{o}}^{15}$ values because of resuspension of MPB (Heckman, 1985). Easley et al. (2005) proposed that this would happen with the arrival of water as the tide rose. More interestingly, experimental draining of the sediment decreased $F_{\mathrm{o}}^{15}$ relative to sediment in situ. This pattern was observed at approximately the same time (around $1.30-2 \mathrm{pm})$ as the M2 time of the previous experiment, when no changes in $F_{\mathrm{o}}^{15}$ values were observed. Thus, although not excluding the occurrence of NPQ processes in this habitat, this result clearly shows that the absence of moisture can decrease fluorescence in soft sediments if the sediment dries out, e.g. during exceptionally low spring tides on particularly hot and dry days. This is in accordance with the negative effect 
of desiccation on measures of fluorescence found by Coelho et al. (2009) in a laboratory study. This would cause a similar pattern to that shown on the rocky shore and also suggests that positive effects of compaction of sediment on fluorescence values are weak or non-existent in this estuary. Data from the same location used here showed a good correlation between MPB biomass and $F_{\mathrm{o}}^{15}$ at two sites during the middle of low tide (with $r^{2}$ values of 0.6 and 0.7 , unpublished data). This means that, as on a rocky shore, moisture content of the sediment can affect the relationship between biomass and $F_{\mathrm{o}}^{15}$. The relationship varied not only from the middle to the end of the period of low tide (which could be due, again, both to NPQ processes and drainage), but also between sites (which probably differ in the amount of moisture of the sediment, despite their apparent similarity). Thus, on soft sediments, the time during the low tide period when one samples using PAM may provide different results depending on the amount of drainage. This varies a lot from place to place on a mudflat, depending on compaction of the sediment, the mix of grain-sizes and small micro-topographic features caused by environmental conditions or actions of biota.

\section{Conclusions}

The two studies described here emphasized the need to sample representatively when using PAM (e.g. to estimate MPB biomass) during low tide. On rocky shores and in soft sediments, it is important to consider the wetness of the substratum. If this cannot be kept consistent across larger temporal scales, it may be important to stratify sampling to incorporate wet and dry patches of habitat or to collect enough samples at each time to ensure that samples are representative of the range of conditions at each time. The latter method would then allow comparisons at different states of the tidal cycle. On rocky shores, the timing of sampling during low tide did not seem to affect the results as long as the substratum was dry. As a consequence, in conditions where the presence of water (e.g. from wave-splash, seepage from rock pools, run-off, etc.) cannot be avoided, the rock surface should be dampened manually, to guarantee that measurements are comparable. Timing of sampling during emersion appears to be more important in sediments than on rock, although this can vary among habitats. In this case, it is probably more difficult to ensure a comparable moisture of the sediment both among sites and times during low tide, without altering other characteristics of the sediment (such as micro-topography, compaction of sediment, micro-spatial variability of MPB). In this case, stratification of sampling and increasing the number of samples at each time during low tide is probably the only way to ensure representativeness of sampling.

In conclusion, when using PAM methodology to estimate MPB biomass, it will be necessary to demonstrate that the time since emersion does not affect the results obtained, rather than simply assume that it does not. All of this indicates that as much thought needs to go into considering small temporal scales of sampling on PAM measurements as has gone into considering small-scale spatial variation. Further investigations are needed to clarify the physiological and/or physical changes occurring inside the MPB cells and/or in the first millimetres of the substratum (rock, mud or sand), which are causing a change in the relationship between fluorescence and MPB biomass in the presence of different amounts of water.

Acknowledgments E.M. was supported by an Italian fellowship from CoNISMa; the entire study was supported by funds from the Australian Research Council through the Centre for Research on Ecological Impacts of Coastal Cities and ARC Discovery Projects to A.J.U. and to M.G.C. and T.T. We thank Paul Devlin and Mark Ellis for assistance in the field and Richard Murphy for information on the MPB communities.

\section{References}

Bailey, S. \& A. Grossman, 2008. Photoprotection in cyanobacteria: regulation of light harvesting. Photochemistry and Photobiology 84: 1410-1420.

Blanchard, G. F., 1990. Overlapping microscale dispersion patterns of meiofauna and microphytobenthos. Marine Ecology Progress Series 68: 101-111.

Blanchard, G. F., J. M. Guarini, F. Orvain \& P. G. Sauriau, 2001. Dynamic behaviour of benthic microalgal biomass in intertidal mudflats. Journal of Experimental Marine Biology and Ecology 264: 85-100.

Campbell, D., V. Hurry, A. K. Clarke, P. Gustafsson \& G. Öquist, 1998. Chlorophyll fluorescence analysis of cyanobacterial photosynthesis and acclimation. Microbiology and Molecular Biology Reviews 62: 667-683.

Castenholz, R., 1961. Effect of grazing on marine littoral diatom populations. Ecology 42: 783-794.

Chapman, M. G. \& T. J. Tolhurst, 2004. The relationship between invertebrate assemblage and bio-dependant 
properties of sediment in urbanized temperate mangrove forests. Journal of Experimental Marine Biology and Ecology 304: 51-73.

Chapman, M. G. \& T. J. Tolhurst, 2007. Relationships between benthic macrofauna and biogeochemical properties of sediment at different spatial scales and among different habitats in mangrove forests. Journal of Experimental Marine Biology and Ecology 343: 96-109.

Coelho, H., S. Vieira \& J. Serôdio, 2009. Effects of desiccation on the photosynthetic activity of intertidal microphytobenthos biofilms as studied by optical methods. Journal of Experimental Marine Biology and Ecology 381: 98-104.

Cohn, S. A., J. F. Farrell, J. D. Munro, R. L. Ragland, R. E. Weitzell \& B. L. Wibisono, 2003. The effect of temperature and mixed species composition on diatom motility and adhesion. Diatom Research 18: 225-243.

Consalvey, M., R. G. Perkins, G. J. C. Underwood \& D. M. Paterson, 2005. Photosynthesis and fluorescence: a beginner's guide for benthic diatomists. Diatom Research 20: $1-22$.

Dring, M. J. \& F. A. Brown, 1982. Photosynthesis of intertidal brown algae during and after periods of emersion: a renewed search for physiological causes of zonation. Marine Ecology Progress Series 8: 301-308.

Easley, J. T., S. N. Hymel \& C. J. Plante, 2005. Temporal patterns of benthic microalgal migration on a semi-protected beach. Estuarine Coastal and Shelf Science 64: 486-496.

Falkowski, P. \& D. A. Kiefer, 1985. Chlorophyll-a fluorescence in phytoplankton - relationship to photosynthesis and biomass. Journal of Plankton Research 7: 715-731.

Golubic, S., 1969. Distribution, taxonomy, and boring patterns of marine endolithic algae. American Zoologist 9: 747-751.

Hader, D.-P., H. Herrmann, J. Schafer \& R. Santas, 1997. Photosynthetic fluorescence induction and oxygen production in two Mediterranean Cladophora species measured on site. Aquatic Botany 56: 253-264.

Hanelt, D., 1992. Photoinhibition of photosynthesis in marine macrophytes of the South China Sea. Marine Ecology Progress Series 82: 199-206.

Hawkins, S. J., R. G. Hartnoll, J. M. Kain \& T. A. Norton, 1992. Plant-animal interactions on hard substrata in the Northeast Atlantic. In John, D. M., S. J. Hawkins \& J. H. Price (eds), Plant-Animal Interactions in the Marine Benthos. Oxford University Press, Oxford: 1-32.

Heckman, C., 1985. The development of vertical migration patterns in the sediments of estuaries as a strategy for algae to resist drift with tidal currents. Internationale Revue der gesamten Hydrobiologie und Hydrographie 70: 151-164.

Helmuth, B. S. T. \& G. E. Hofmann, 2001. Microhabitats, thermal heterogeneity, and patterns of physiological stress in the rocky intertidal zone. Biological Bulletin 201: 374-384.

Helmuth, B., C. D. G. Harley, P. M. Halpin, M. O’Donnell, G. E. Hofmann \& C. A. Blanchette, 2002. Climate change and latitudinal patterns of intertidal thermal stress. Science 298: 1015-1017.

Henley, W. J., S. T. Lindley, G. Levavasseur, C. B. Osmond \& J. Ramus, 1992. Photosynthetic response of Ulva rotundata to light and temperature during emersion on an intertidal sand flat. Oecologia 89: 516-523.
Hill, A. S. \& S. J. Hawkins, 1990. An investigation of methods for sampling microbial films on rocky shores. Journal of the Marine Biological Association of the United Kingdom 70: 77-88.

Honeywill, C., D. M. Paterson \& S. E. Hagerthey, 2002. Determination of microphytobenthic biomass using pulseamplitude modulated minimum fluorescence. European Journal of Phycology 37: 485-492.

Houpt, P. M., 1994. Marine tube-dwelling diatoms and their occurrence in the Netherlands. Netherland Journal of Aquatic Ecology. 28: 77-84.

Huppertz, K., D. Hanelt \& W. Nultsch, 1990. Photoinhibition of photosynthesis in the marine brown alga Fucus serratus as studied in field experiments. Marine Ecology Progress Series 66: 175-182.

Hutchinson, N. S., J. C. Nagarkar, J. C. Aitchison \& G. A. Williams, 2006. Microspatial variation in marine biofilm abundance on intertidal rock surfaces. Marine Ecology Progress Series 42: 187-197.

Jackson, A. C., R. J. Murphy \& A. J. Underwood, 2009. Patiriella exigua: grazing by a starfish in an overgrazed intertidal system. Marine Ecology Progress Series 376: 153-163.

Jackson, A. C., A. J. Underwood, R. J. Murphy \& G. A. Skilleter, 2010. Latitudinal and environmental patterns in abundance and composition of epilithic microphytobenthos. Marine Ecology Progress Series 417: 27-38.

Jenkins, S. R., F. Arenas, J. Arrontes, J. Bussel, J. Castro, R. A. Coleman, S. J. Hawkins, S. Kay, B. Martinez, M. F. Roberts, S. Sousa, R. C. Thompson \& R. G. Hartnoll, 2001. European-scale analysis of seasonal variability in limpet grazing activity and microalgal abundance. Marine Ecology Progress Series 211: 193-203.

Jesus, B., V. Brotas, M. Marani \& D. M. Paterson, 2005. Spatial dynamic of microphytobenthos determined by PAM fluorescence. Estuarine Coastal and Shelf Science 65: 30-42.

Jesus, B., R. G. Perkins, M. Consalvey, V. Brotas \& D. M. Paterson, 2006. Effects of vertical migrations by benthic micro-algae on fluorescence measurements of photophysiology. Marine Ecology Progress Series 315: 55-66.

Ji, Y. \& J. Tanaka, 2002. Effect of desiccation on the photosynthesis of seaweeds from the intertidal zone in Honshu, Japan. Phycological Research 50: 145-153.

Joint, I. R., J. M. Gee \& R. M. Warwick, 1982. Determination of fine-scale vertical distribution of microbes and meiofauna in an intertidal sediment. Marine Biology 72: 157-162.

Kromkamp, J., C. Barranguet \& J. Peene, 1998. Determination of microphytobenthos PSII quantum efficiency and photosynthetic activity by means of variable chlorophyll fluorescence. Marine Ecology Progress Series 162: 45-55.

Lamontagne, I., A. Cardinal \& L. Fortier, 1989. Environmental forcing versus endogenous control of photosynthesis in intertidal epilithic micro-algae. Marine Ecology Progress Series 51: 177-187.

MacIntyre, H. L. \& J. J. Cullen, 1996. Primary production by suspended and benthic micro-algae in a turbid estuary: time-scales of variability in San Antonio Bay, Texas. Marine Ecology Progress Series 145: 245-268.

MacIntyre, H. L., R. J. Geider \& D. C. Miller, 1996. Microphytobenthos: the ecological role of the "Secret Garden" of unvegetated, shallow-water marine habitats. I. Distribution, abundance and primary production. Estuaries 19: 186-201. 
Magalhães, C. M., A. A. Bordalo \& W. J. Wiebe, 2003. Intertidal biomass on rocky substratum can play a major role in estuarine carbon and nutrient dynamics. Marine Ecology Progress Series 258: 275-281.

Murphy, R. J., T. Tolhurst, M. G. Chapman \& A. J. Underwood, 2004. Estimation of surface chlorophyll on an exposed mudflat using digital colour-infrared (CIR) photography. Estuarine Coastal and Shelf Science 59: 625-638.

Murphy, R. J., A. J. Underwood, M. H. Pinkerton \& P. Range, 2005a. Field spectrometry: new methods to investigate epilithic micro-algae on rocky shores. Journal of Experimental Marine Biology and Ecology 325: 111-124.

Murphy, R. J., T. J. Tolhurst, M. G. Chapman \& A. J. Underwood, 2005b. Estimation of surface chlorophyll- $a$ on an emersed mudflat using field spectrometry: accuracy of ratios and derivative-based approaches. International Journal of Remote Sensing 26: 1835-1859.

Murphy, R. J., A. J. Underwood \& M. H. Pinkerton, 2006. Quantitative imaging to measure photosynthetic biomass on an intertidal rock-platform. Marine Ecology Progress Series 312: 45-55.

Nagarkar, S. \& G. A. Williams, 1999. Spatial and temporal variation of cyanobacteria-dominated epilithic communities on a tropical shore in Hong Kong. Phycologia 38: 385-393.

Nicotri, M. E., 1977. Grazing effects of 4 marine intertidal herbivores on microflora. Ecology 58: 1020-1032.

Perkins, R. G., G. J. C. Underwood, V. Brotas, G. C. Snow, B. Jesus \& L. Ribeiro, 2001. Responses of microphytobenthos to light: primary production and carbohydrate allocation over an emersion period. Marine Ecology Progress Series 223: 101-112.

Perkins, R. G., C. Honeywill, M. Consalvey, A. J. Austin, T. J. Tolhurst \& D. M. Paterson, 2003. Changes in microphytobenthic chlorophyll $a$ and EPS resulting from sediment compaction due to de-watering: opposing patterns in concentration and content. Continental Shelf Research 23: 575-586.

Roncarati, F., J. W. Rijstenbil \& R. Pistocchi, 2008. Photosynthetic performance, oxidative damage and antioxidants in Cylindrotheca closterium in response to high irradiance, UVB radiation and salinity. Marine Biology 153: 965-973.

Round, F. E. \& J. D. Palmer, 1966. Persistent, vertical migration rhythms in benthic microflora. II. Field and laboratory studies on diatoms from the banks of the river Avon. Journal of the Marine Biological Association of United Kingdom 46: 191-214.

Saburova, M. A., I. G. Polikarpov \& I. V. Burkovsky, 1995. Spatial structure of an intertidal microphytobenthic community as related to different spatial scales. Marine Ecology Progress Series 129: 229-239.

Serôdio, J. \& F. Catarino, 2000. Modelling the primary productivity of intertidal microphytobenthos: time scales of variability and effects of migratory rhythms. Marine Ecology Progress Series 192: 13-30.

Serôdio, J., J. Marques da Silva \& F. Catarino, 1997. Nondestructive tracing of migratory rhythms of intertidal benthic micro-algae using in vivo chlorophyll $a$ fluorescence. Journal of Phycology 33: 542-553.

Serôdio, J., S. Vieira, S. Cruz \& F. Barroso, 2005. Short-term variability in the photosynthetic activity of microphytobenthos as detected by measuring rapid light curves using variable fluorescence. Marine Biology 146: 903-914.

Sullivan, M. J. \& C. A. Moncrieff, 1988. A multivariate analysis of diatom community structure and distribution in a Mississippi salt marsh. Botanica Marina 31: 93-99.

Suzuky, L. \& C. H. Johnson, 2001. Algae know the time of the day: circadian and photoperiodic programs. Journal of Phycology 37: 933-942.

Thompson, R. C., T. A. Norton \& S. J. Hawkins, 2004. Physical stress and biological control regulate the producer-consumer balance in intertidal biofilms. Ecology 85: 1372-1382.

Thompson, R. C., P. S. Moschella, S. R. Jenkins, T. A. Norton \& S. J. Hawkins, 2005. Differences in photosynthetic marine biofilms between sheltered and moderately exposed rocky shores. Marine Ecology Progress Series 296: 53-63.

Tolhurst, T. J. \& M. G. Chapman, 2005. Spatial and temporal variation in the sediment properties of an intertidal mangrove forest: implications for sampling. Journal of Experimental Marine Biology and Ecology 317: 213-222.

Tolhurst, T. J. \& M. G. Chapman, 2007. Patterns in biogeochemical properties of sediments and benthic animals among different habitats in mangrove forests. Austral Ecology 32: 775-788.

Tolhurst, T. J., B. Jesus, V. Brotas \& D. M. Paterson, 2003. Diatom migration and sediment armouring - an example from the Tagus Estuary, Portugal. Hydrobiologia 503: 183-193.

Tolhurst, T. J., E. C. Defew, R. G. Perkins, A. Sharples \& D. M. Paterson, 2006. The effects of tidally-driven temporal variation on measuring intertidal cohesive sediment erosion threshold. Aquatic Ecology 40: 521-531.

Underwood, A. J., 1980. The effects of grazing by gastropods, and physical factors on the upper limits of distribution of intertidal macroalgae. Oecologia 46: 201-213.

Underwood, A. J., 1984a. The vertical-distribution and seasonal abundance of intertidal micro-algae on a rocky shore in New South Wales. Journal of Experimental Marine Biology and Ecology 78: 199-220.

Underwood, A. J., 1984b. Vertical and seasonal patterns in competition for micro-algae between intertidal gastropods. Oecologia 64: 211-222.

Underwood, A. J., 1997. Ecological Experiments: Their Logical Design and Interpretation Using Analysis of Variance. Cambridge University Press, Cambridge.

Underwood, G. C. J. \& J. Kromkamp, 1999. Primary production by phytoplankton and microphytobenthos in estuaries. Advances in Ecological Research 29: 93-153.

Underwood, G. C. J., R. G. Perkins, M. C. Consalvey, A. R. M. Hanlon, K. Oxborough, N. R. Baker \& D. M. Paterson, 2005. Patterns of microphytobenthic primary productivity: species-specific variation in migratory rhythms and photosynthetic efficiency in mixed-species biofilms. Limnology and Oceanography 50: 755-767.

Yallop, M. L., B. D. Winder, D. M. Paterson \& L. J. Stal, 1994. Comparative structure, primary production and biogenic stabilization of cohesive and non-cohesive marine sediments inhabited by microphytobenthos. Estuarine Coastal and Shelf Science 39: 565-582. 